\title{
Distribution of mangrove red snapper, Lutjanus argentimaculatus in relation to hydrodynamic condition at the patch reefs of Lankayan, Sugud Islands Marine Conservation Area, Sabah, Malaysia
}

\author{
Davies Austin Spiji1,2, B. Mabel Manjaji-Matsumoto ${ }^{1 *}$ and Zarinah Waheed ${ }^{1}$ \\ ${ }^{1}$ Endangered Marine Species Research Unit Borneo Marine Research Institute, Universiti Malaysia Sabah, Jalan \\ UMS, 88400 Kota Kinabalu, Sabah, Malaysia \\ ${ }^{2}$ Reef Guardian Sdn. Bhd., 1st Floor, Block C, Lot 38, Bandar Tyng, Mile 6, 90000 Sandakan, Sabah, Malaysia.
}

\section{*Corresponding author: mabel@ums.edu.my}

\begin{abstract}
The mangrove red snapper, Lutjanus argentimaculatus is a prized food-fish in the tropical and subtropical fisheries, as well as the aquaculture industry. This study investigated the distribution of L. argentimaculatus at three patch reefs of Lankayan Island, within the Sugud Islands Marine Conservation Area. Fish surveys were conducted 12 times at each of the selected patch reefs, from August 2016 until March 2017. Underwater video footages, hydrodynamic parameters (current direction and current speed) were recorded during each survey. The distribution patterns of the fish were plotted against these parameters to determine any correlation, in response to these parameters. There was a significant relationship between the current direction and the position of red mangrove snapper at the reef where schoolings were found to occur. We found that regardless of the current speed, the schools of red mangrove snapper were always present at the reef slope facing the oncoming current. This finding is important for the management and conservation of this species, which is a targeted species in the Live Reef Food Fish Trade (LRFFT), and is useful for the management of a Marine Protected Area (MPA) in general. This finding is also important as it provides useful insights into the ecology of mangrove red snapper.
\end{abstract}

Keywords: Mangrove red snapper, Lutjanus argentimaculatus, Ocean current, Patch reef, Hydrodynamic condition, Sabah

\section{Introduction}

The mangrove red snapper, Lutjanus argentimaculatus (Forsskål, 1775), is one of 113 extant species of mostly reefdwelling marine fishes under the family Lutjanidae (Fricke et. al., 2019; Nelson et. al., 2016). This Indo-Pacific species of the genus Lutjanus is distributed throughout tropical and subtropical areas, from the Red Sea and eastern Africa to Samoa and Line Island in eastern central Pacific waters, and from southwest Japan to southeast Australia; it has presumably dispersed from the northern Red Sea into the eastern Mediterranean coast of Lebanon through the Suez Canal (Allen, 1985). This snapper either occurs individually or forms loose aggregations (Allen, 1985; Allen et al., 2003). Like most large-sized lutjanids, mangrove red snapper is prized for its value throughout its widespread geographical range in commercial and artisanal fisheries, as well as in recreational fishing activities (Allen, 1985). It is also suitable for aquaculture, especially in the Southeast Asian region, where production is primarily done in Hong Kong, Malaysia, Singapore, Taiwan and Thailand (Coniza et al., 2012; Othman, 2010). The juveniles and adolescents of mangrove red snapper typically occur at nursery habitats of brackish estuaries and lower reaches of freshwater streams, while larger fishes, mostly adults, undergo ontogenetic migration offshore to deeper areas of up to $100 \mathrm{~m}$ depth, and spawn at these habitats (Allen, 1985; Russell et al., 2003; Russell and McDougall, 2005). Though few studies have clarified on the movement of mangrove red snapper inshore, inter-coastal habitats and offshore, there is paucity of information on the movement of this species within the offshore habitats. Due to its popularity in fisheries and aquaculture, this species may face local depletion due to overharvesting of juveniles for aquaculture industry, and overfishing of adults for fisheries (Russell and McDougall, 2008; Chi, 2017). This study investigated the distribution of mangrove red snapper within patch reefs to understand its ecological behaviour and to gain clearer perspective of its movement at the reef habitats. Such study would be crucial for the conduct of effective fisheries management.

\section{Materials and Methods}

\section{Study sites}

The study sites were situated at the selected reefs of Lankayan, in the Sugud Islands Marine Conservation Area (SIMCA), a no-take zone marine protected area located within Malaysian Sulu Sea, and the Coral Triangle (Figure 1).

SIMCA is located approximately $80 \mathrm{~km}$ from Sandakan main town, covering 46,317 hectares and is characterised by shallow reefs, seagrass beds and sandy bottom (Reef Guardian Sdn. Bhd., 2015). Three patch reefs, namely Froggie Fort (6³0'19.548" N, 117 $55^{\prime} 1.092^{\prime \prime}$ E), Ikok Rock $\left(6^{\circ} 28^{\prime} 53.22^{\prime \prime} \mathrm{N}, 117^{\circ} 53^{\prime} 33.072^{\prime \prime} \mathrm{E}\right)$ and Goby Rock $\left(6^{\circ} 28^{\prime} 44.4^{\prime \prime}\right.$ $\mathrm{N}, 117^{\circ} 53^{\prime} 26.88^{\prime \prime} \mathrm{E}$ ), were selected as sampling sites. These reefs have almost similar depth, from about $10 \mathrm{~m}$ at the reef top down to about $20 \mathrm{~m}$ at the reef base. 


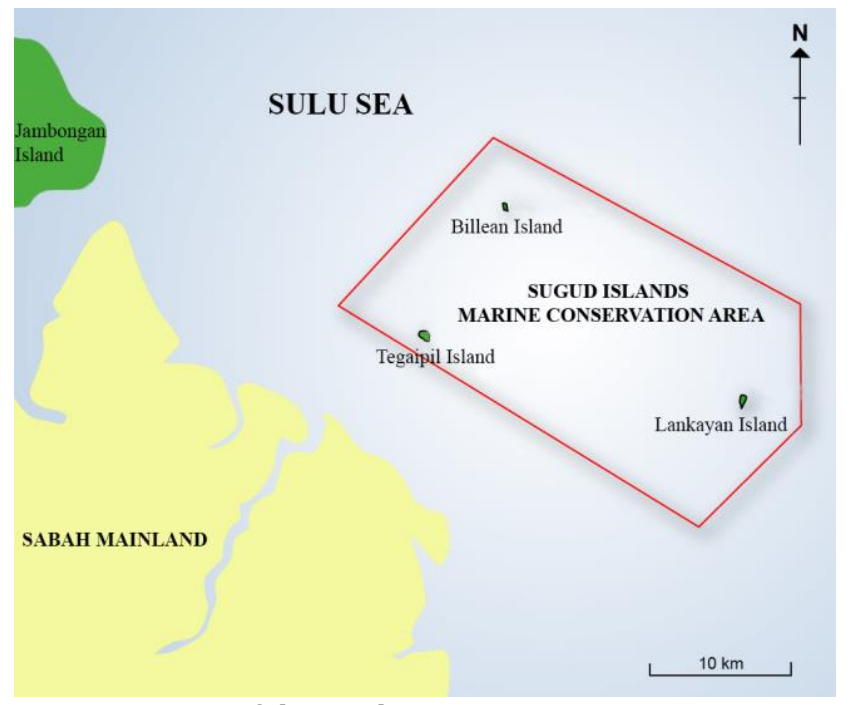

Figure 1. Map of the study area.

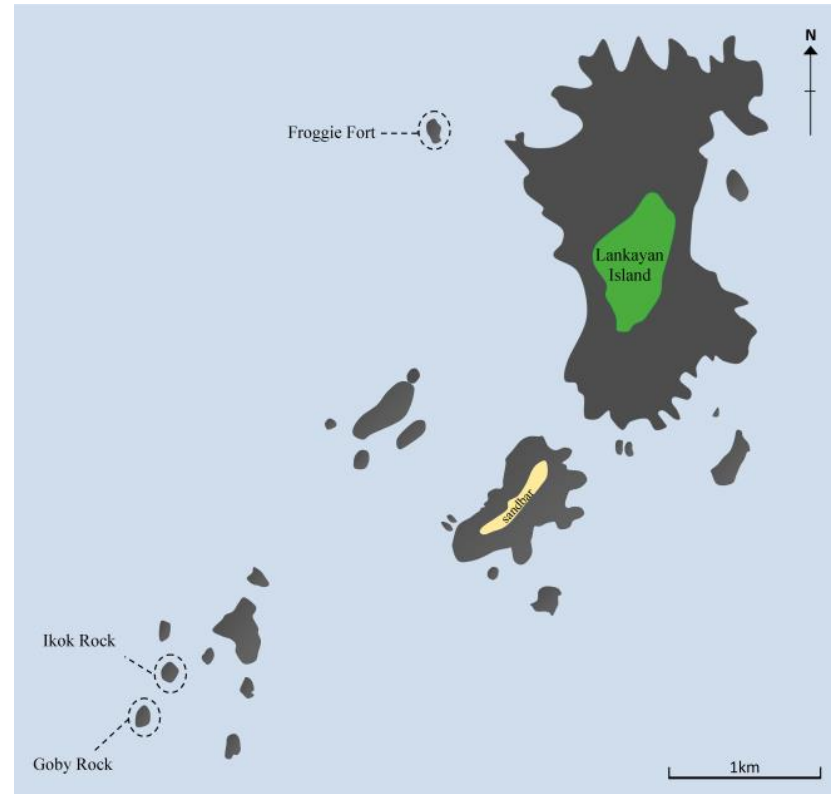

Figure 2. Map of survey sites.

\section{Underwater fish census}

The underwater fish censuses were conducted 12 times at each sampling sites, within the period from $17^{\text {th }}$ August 2016 until 22nd March 2017. Each of the selected reefs was surveyed entirely, by circling the reef along the reef slopes before surveying the reef top. Two divers were required to conduct the census, with each diver carrying out a specific task: the first diver conducted slate recording, while the second diver conducted video recording (using GoPro Hero $3+$ ), especially on the schooling formation of mangrove red snapper to assist fish count.

\section{Hydrodynamic Condition}

The water current direction at the reef was measured using a triangular-shaped flag and a compass, where the tip of the flag pointed to the direction of the current. As for the relative current speed $\left(\mathrm{m} \mathrm{s}^{-1}\right)$, a syringe containing coloured vinegar was used by measuring the distance, in metre (m), at which the coloured vinegar travelled in one second (s). Vinegar was chosen as it does not dissipate quickly into the water.

\section{Statistical data analyses}

IBM SPSS Statistics version 21 was used to analyse all the data. Non-parametric chi-square test for goodness of fit tests were applied to see the significance of difference at $\mathrm{p}<0.05$, if any, of the frequency of current direction, and current speed, with respect to mangrove red snapper's position at the reef.

\section{Results and Discussion}

\section{Current direction vs. distribution of mangrove red snapper at the reefs}

During the fish observational survey, the distribution of mangrove red snapper at the reef was found at (i) reef slope facing oncoming current, (ii) reef slope facing perpendicular to current flow, (iii) reef slope facing outgoing current, and (iv) under coral or boulder, throughout the survey period (Figure 3,4). The chi-square goodness of fit test indicated that there was a significant difference $(p=0.000)$ in frequency of mangrove red snapper's position at the reef towards the current direction, where $83.92 \%$ of the fish occurred at the reef sections facing the oncoming current, $\mathrm{X}^{2}$ $(3, \mathrm{n}=336)=628.024$.

This result was largely contributed by the data from Ikok Rock, as the abundance of this species was higher at Ikok Rock (mean $=25.92$ indv., SD $=15.84$ ) than Froggie Fort (mean $=0.42, \mathrm{SD}=0.51)$ and Goby Rock (mean $=1.92, \mathrm{SD}=$ 1.83), and though the species were consistently present at Ikok Rock, it was absent at Froggie Fort during 7 observational surveys, and at Goby Rock during 3 observational surveys. This species was often found as solitary individual at Froggie Fort and Goby Rock, where they were frequently found under boulders or corals, especially at Goby Rock. At Ikok Rock, mangrove red snapper were usually found in schools, where the snappers frequented the reef sections facing oncoming current. The juvenile mangrove red snappers inhabit the riverine and estuarine environment (Russel et al., 2003; Russel and McDougall, 2005; Chi and True, 2017), where they are adapted to deal with currents that is mainly one-dimensional than the usually weaker, and multidimensional flow in the oceanic environment (Grubbs and Kraus, 2010). Hence, the mangrove red snappers might develop the affinity for underwater currents, and retain such behaviour even when they migrate ontogenetically offshore. This adaptation might play a critical role in their feeding behaviour like in many fluvial fishes. Trout, for instance, uses drift feeding as foraging tactic, in which it maintains a steady upstream facing position while searching for downstream drifting prey to intercept (Jenkins, 1969; Kanter and Coombs, 2003). The mangrove red snapper may potentially adopt this feeding behaviour, which may continue on when they migrate into the reef system. The same cannot be said for the individuals that were observed to be hiding under the rock outcrops or corals, as their presence in low abundance might make them vulnerable to threats of predation as opposed to schools, where mechanism for anti-predator defence can be established (Magurran, 1990). Rock outcrops and corals can offer refuge to these individuals. Tabular corals, for example, conceal and provide shelter to large-bodied reef fishes from predators and also allowing quick escape (Kerry and Bellwood, 2012). 


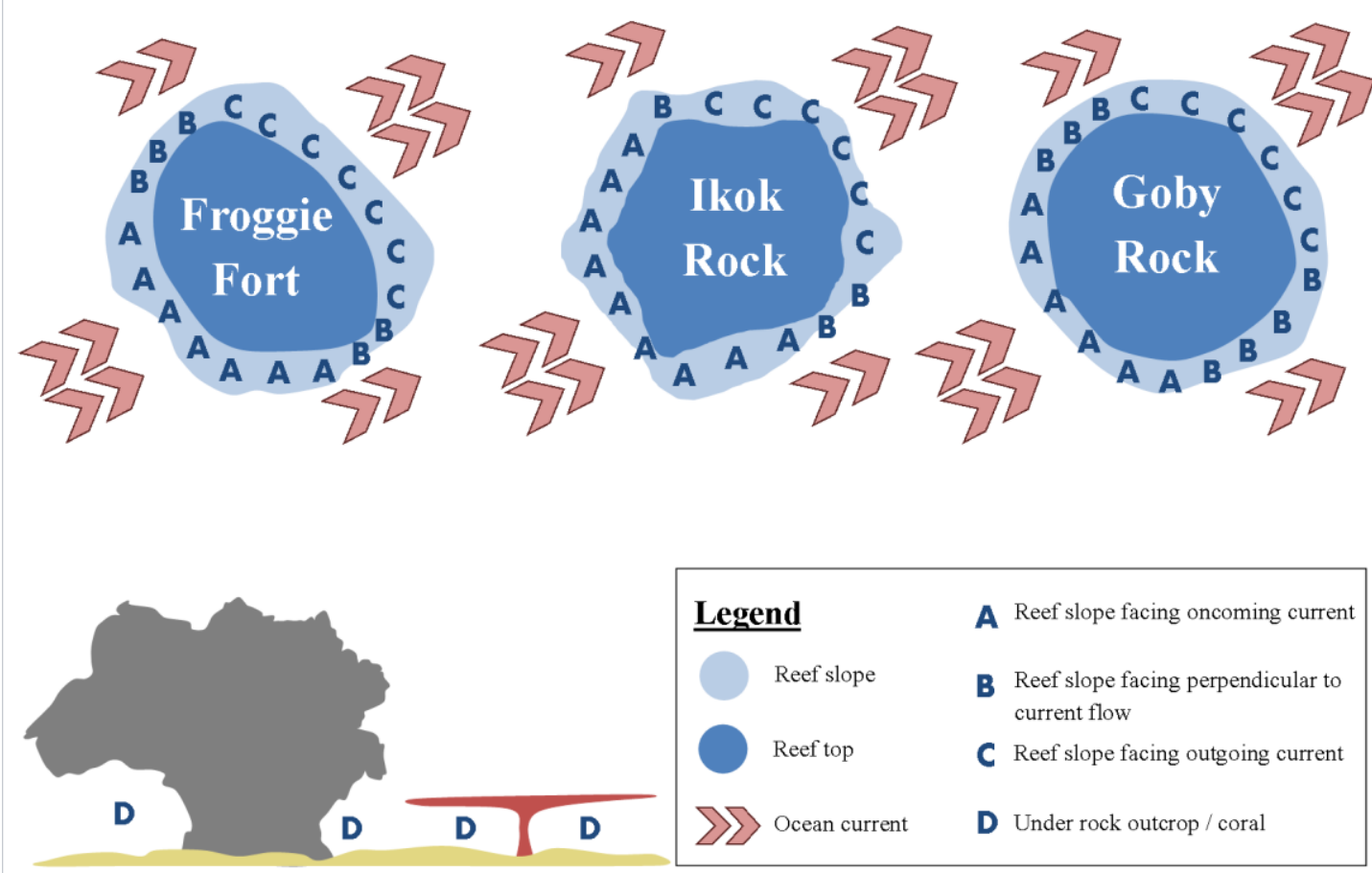

Figure 3. Categories of mangrove red snapper's position observed at the survey sites. The direction of ocean currents varied throughout the sampling period. The current direction depicted in this figure is merely an example to show the breakdown of reef slope sections with respect to current direction.

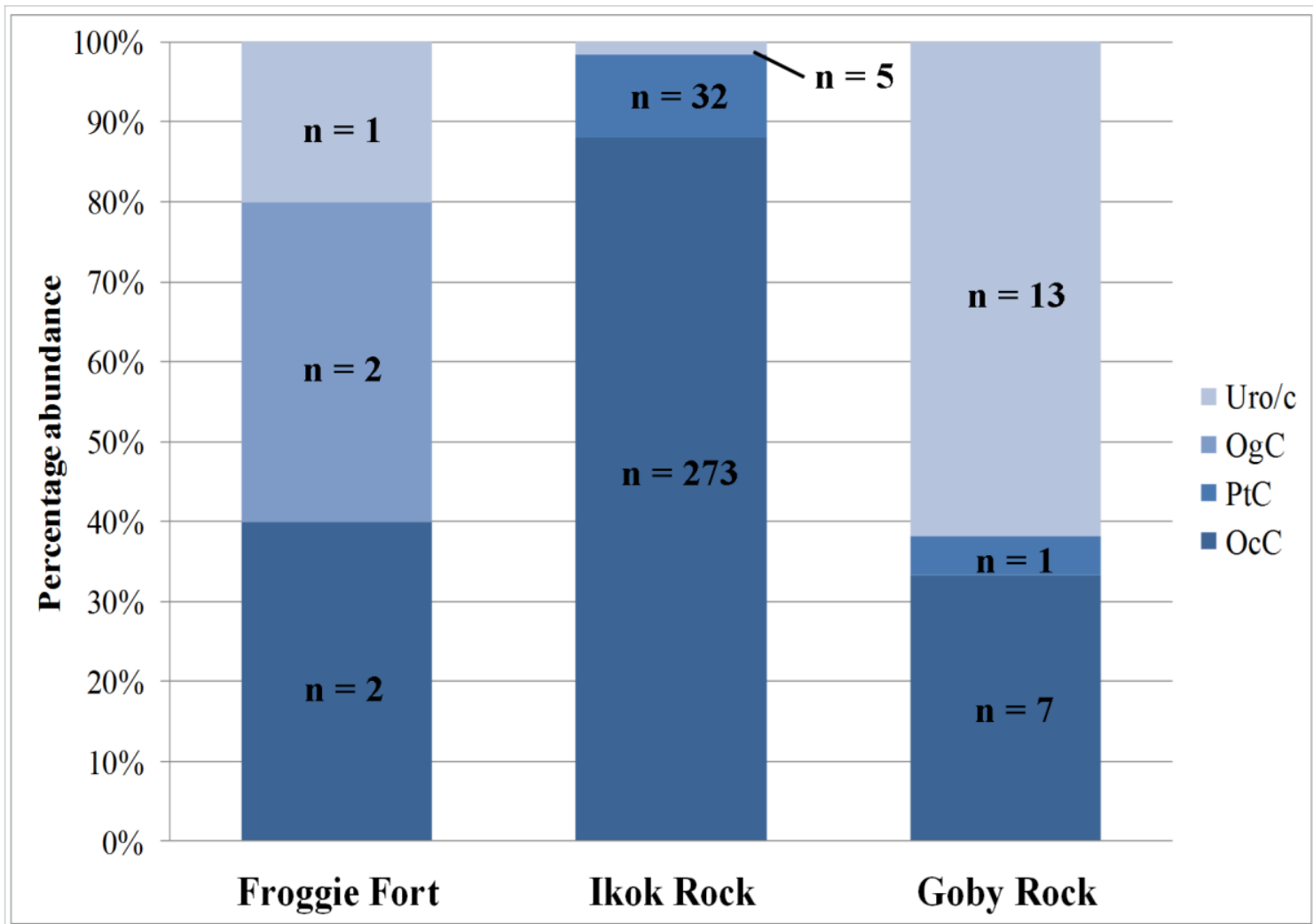

Figure 4. Percentage of abundance of mangrove red snapper found at different sections of the reef in response to current direction $(\mathrm{OcC}=$ Reef slope facing oncoming current, $\mathrm{PtC}=$ Reef slope facing perpendicular to current, $\operatorname{OgC}=$ Reef slope facing outgoing current, Uro/c = Under rock outcrop/coral) 


\section{Current speed vs. distribution of mangrove red snapper at the reefs}

Throughout the surveys, the current speed recorded was in a range from $0.0005 \mathrm{~m} \mathrm{~s}^{-1}$ to $0.39 \mathrm{~m} \mathrm{~s}^{-1}$. Based on this range, the current speed was categorised into two classes of intensity: 0 $<\mathrm{x} \leq 0.20 \mathrm{~m} \mathrm{~s}^{-1}$ (Noccurrence $\left.=16\right), 20<\mathrm{x} \leq 0.40 \mathrm{~m} \mathrm{~s}^{-1}$ (Noccurrence $=9)$. The chi-square goodness of fit test indicated significant relationship in the frequency of mangrove red snapper's position at the reef at both of the current speed classes $(\mathrm{p}=$ 0.000 , respectively), where the fish frequented at the reef sections facing the oncoming current by $83.33 \%$ at the current speed of $0<\mathrm{x} \leq 0.20 \mathrm{~m} \mathrm{~s}^{-1}, \mathrm{X}^{2}(3, \mathrm{n}=234)=429.214$, and $85.29 \%$ at the current speed of $20<\mathrm{x} \leq 0.40 \mathrm{~m} \mathrm{~s}^{-1}, \mathrm{X}^{2}(2$, $n=102)=123.941$. Hence, this indicated that mangrove red snapper, especially in schooling formation, preferred the reef slopes facing the oncoming current regardless the current speed.

\section{Conclusion}

The affinity for the ocean currents were exhibited in the schooling mangrove red snapper, where their occurrence were found at the reef slope facing against the oncoming current. This was regardless of the speed intensity, presumably as they are accustomed to the rather constant current flow at riverine and estuarine habitats that they settle in when they were young. This behaviour, however, was not the same when they swim individually or in small groups, where they were relatively more cryptic by swimming under boulders or corals, possibly to protect themselves from predation. These findings serve as insights on how this species is distributed on a reef, which can be helpful in understanding its response to its reef ecology and to better manage its population in the wild from depletion due to increasing fishing pressure.

\section{Acknowledgement}

This study received funding support from UMSGreat (Project code: GUG0006-STWN-M-1/2016). We wish to acknowledge Reef Guardian Sdn. Bhd. for permitting the study to be undertaken within SIMCA, and for providing additional facilities and equipment for this study. Our special thanks to Dr. Achier Chung and Miss Leony Sikim for their assistance throughout the sampling period.

\section{References}

Allen, G. R. (1985). FAO species catalogue. Vol 6. Snappers of the world. An annotated and illustrated catalogue of lutjanid species known to date. In: FAO Fish. Synopsis No. 125, Vol. 6. p 28. FAO Fisheries 6(125), 24-29.

Allen, G. R., Steene, R., Humann, P., \& Deloach, N. (2003). Reef Fish Identification - Tropical Pacific Fishes. Jacksonville, Florida, USA: New World Publications, Inc.

Bentley, N. (1999). Fishing for Solutions - Can the live trade in wild groupers and wrasses from Southeast Asia be managed? TRAFFIC Southeast Asia, Kuala Lumpur.

Chi, V. V., \& True, J. D. (2017). Recruitment and habitat ecology of juvenile mangrove red snapper (Lutjanus argentimaculatus Forsskal, 1775) in central Vietnam. International Journal of Fisheries and Aquatic Studies 5(6), 103-107.
Chi, V. V. (2017). Habitat Specifity \& Feeding Ecology of Juvenile Mangrove Snapper (Lutjanus argentimaculatus Forsskal, 1775). PhD Thesis. Hat Yai, Thailand: Prince of Songkla University.

Coniza, E. B., Catacutan, M. R., \& Caballero, P. A. (2012). Grow-out culture of mangrove red snapper (Lutjanus argentimaculatus Forsskal, 1775 ) in ponds. In Aquaculture Extension Manual. Retrieved from https://www.seafdec.org.ph/ on 7 January 2019.

Fricke, R., Eschmeyer, W. N., \& Fong, J. D. (eds.) (2019). Eschmeyer's Catalog of Fishes: Genera, Species, References. Retrieved from http://researcharchive.calacademy.org/research/ichthyology/catalog/ SpeciesByFamily.asp on 12 January 2019.

Grubbs, R. D., \& Kraus, R. T. (2010). Fish migration. In Encyclopedia of Animal Behavior 1, 715-724. DOI: 10.1016/B978-0-12-809633-8.01247-4

Jenkins, T. M. (1969). Social Structure, Position Choice and Microdistribution of Two Trout Species (Salmo trutta and Salmo gairdneri) Resident in Mountain Streams. Animal Behaviour Monographs 2, 55-123. DOI: $10.1016 / \mathrm{s} 0066-1856(69) 80002-6$

Kanter, M. J., \& Coombs, S. (2003). Rheotaxis and prey detection in uniform currents by Lake Michigan mottled sculpin (Cottus bairdi). Journal of Experimental Biology 206(1), 59-70. DOI: 10.1242/jeb.00056

Kerry, D. R., \& Bellwood, J. T. (2012). The effect of coral morphology on shelter selection by coral reef fishes. Coral Reefs 31, 415-424. DOI: 10.1007/s00338-011-0859-7

Magurran, A. E. (1990). The adaptive significance of schooling as an anti-predator defence in fish. Finnish Zoological and Botanical Publishing Board 27(2), 51-66.

Nelson, J. S., Grande, T. C., \& Wilson, M. V. H. (2016). Fishes of the World (5th ed.). DOI: 10.1002/9781119174844

Othman, F. (2010). Challenges ahead in meeting aquaculture production in Malaysia under the third National Agricultural Policy NAP3 (1998-2010) Brackish Water Aquaculture Research Center, Department of Fisheries Malaysia, Johor. Retrieved from http://www.fftc.agnet.org/htmlarea_file/ activities/20110719101541/12.pdf on 24 January 2019.

Russell, D. J., McDougall, A. J. (2008). Reproductive biology of mangrove jack (Lutjanus argentimaculatus) in northeastern Queensland, Australia. New Zealand Journal of Marine and Freshwater Research 42(2), 219232. DOI: $10.1080 / 00288330809509950$

Russell, D. J., \& McDougall, A. J. (2005). Movement and juvenile recruitment of mangrove jack, Lutjanus argentimaculatus (Forsskål), in northern Australia. Marine and Freshwater Research 56(4), 465-475. DOI: $10.1071 /$ MF04222

Russell, D. J., McDougall, A. J., Fletcher, A. S., Ovenden, J. R., \& Street, R. (2003). Biology, Management and Genetic Stock Structure of Mangrove Jack (Lutjanus argentimaculatus) in Australia. Brisbane: Queensland Department of Primary Industries. 